\title{
Advances in Optical Microscopy Austenitic Characterization by Combination of Different Chemical Etchings
}

Víctor Mercado ${ }^{1}$, Raúl Perez ${ }^{1}$, Bryan Ramiro-Rodriguez ${ }^{2}$, Juan Carlos Díaz-Guillén ${ }^{3}$, Hugo Arcos-

Gutierrez $^{4}$, Jan Mayen ${ }^{4}$, Jose Antonio Betancourt-Cantera ${ }^{1}$, Adriana Gallegos-Melgar ${ }^{1}$, Maricruz Hernandez-Hernandez ${ }^{1}$ and Isaias Garduño-Olvera ${ }^{4}$

${ }^{1}$ CONACYT-Corporación Mexicana de Investigación en Materiales, San Luis Potosí, San Luis Potosi, Mexico, ${ }^{2}$ Corporación Mexicana de Investigación en Materiales, Saltillo, Coahuila de Zaragoza, Mexico, ${ }^{3}$ CONACYT-Corporación Mexicana de Investigación en Materiales, Saltillo, Coahuila de Zaragoza, Mexico, ${ }^{4}$ CONACYT-Centro de Tecnologia Avanzada, San Luis Potosi, San Luis Potosi, Mexico

The new advances about optical microscopy characterization usually involves complicate techniques (laser and electrolytic etching) that many times are not feasible to replicate for researchers around the world. In this context, it is evident the necessity for improve the uncomplicate characterizations. Chemical etching is one of the uncomplicate techniques in order to reveal the microstructure in many materials as is the case of austenitic steels. Actually, austenitic steels are one of the most used materials for different applications in a wide ranging from food processing industry to nuclear reactors [1-3].

The present research work deals with a new combination of different chemicals in or order to reveal the microstructure, with good quality resolution in one of the most used commercial austenitic steels as is the case of AISI 304 stainless steel, for this purpose it was used the chemical etching called "aqua regia" $\left(\mathrm{HNO}_{3}+\mathrm{HCl}\right)$ mixed with "potassium metabisulfite" $\left.\mathrm{K}_{2} \mathrm{~S}_{2} \mathrm{O}_{5}\right)$.

The process begins with the polishing of samples until $1 \mu \mathrm{m}$ diamond paste, follow by chemical etching as show in Table 1. In this way, it is important to mention that all specimens were etching using the immersion technique in order to have the best results.

Table 1. Steps to follow for the different chemical etchings.

$\begin{array}{cccc}\text { Chemical etching name } & \text { Composition } & \text { Concentration } & \text { Time } \\ \text { Aqua regia } & \mathrm{HNO} 3+\mathrm{HCl} & 20 \mathrm{ml} \mathrm{HNO}+60 \mathrm{ml} & 60 \mathrm{~s} \\ \text { Potassium metabisulfite } & \mathrm{K}_{2} \mathrm{~S}_{2} \mathrm{O}_{5} & \mathrm{HCl} & 60 \mathrm{~s}\end{array}$

Fig. 1 shows optical micrograph of the "aqua regia" etching in the austenitic AISI 304 stainless steel, where is possible to see grain boundaries and twins with not good quality resolution but can be improve in Fig. 2, with the combination of "aqua regia" and "potassium metabisulfite", where is possible to detect the same characteristics as grain boundaries and twins in a good quality resolution. It is also worth noting that only bright field was used in all cases to take the pictures, showing and important advance in this knowledge field, where many times is required to use other optical techniques as: darkfield illumination, interference contrast, polarized light and others [4].

Results shown that the good combination of chemical etching can be help to improve better optical images in order to characterize microstructural structures, that many times does not have the minimum quality required as can de seen in this research work is possible to optimize in austenitic structures. On the other 
hand, it was possible to reveal the microstructure with good quality resolution in the AISI 304 stainless steel, making use of the combination between "aqua regia" and "potassium metabisulfite" [5].

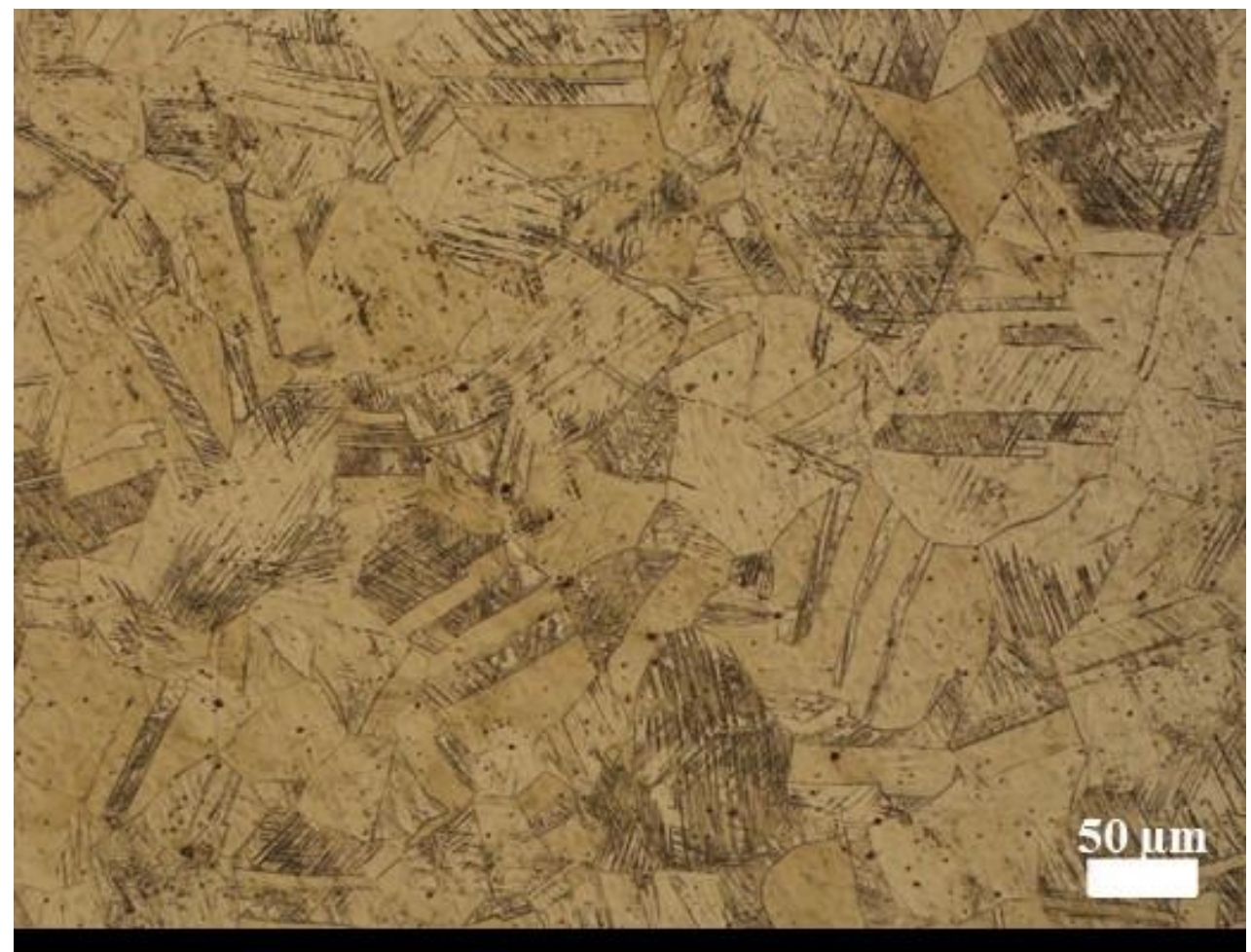

Figure 1. Bright field of optical micrographs at 200x magnification in the AISI 304 stainless steel using "aqua regia" ( $\mathrm{HNO} 3+\mathrm{HCl})$ as the chemical etching.

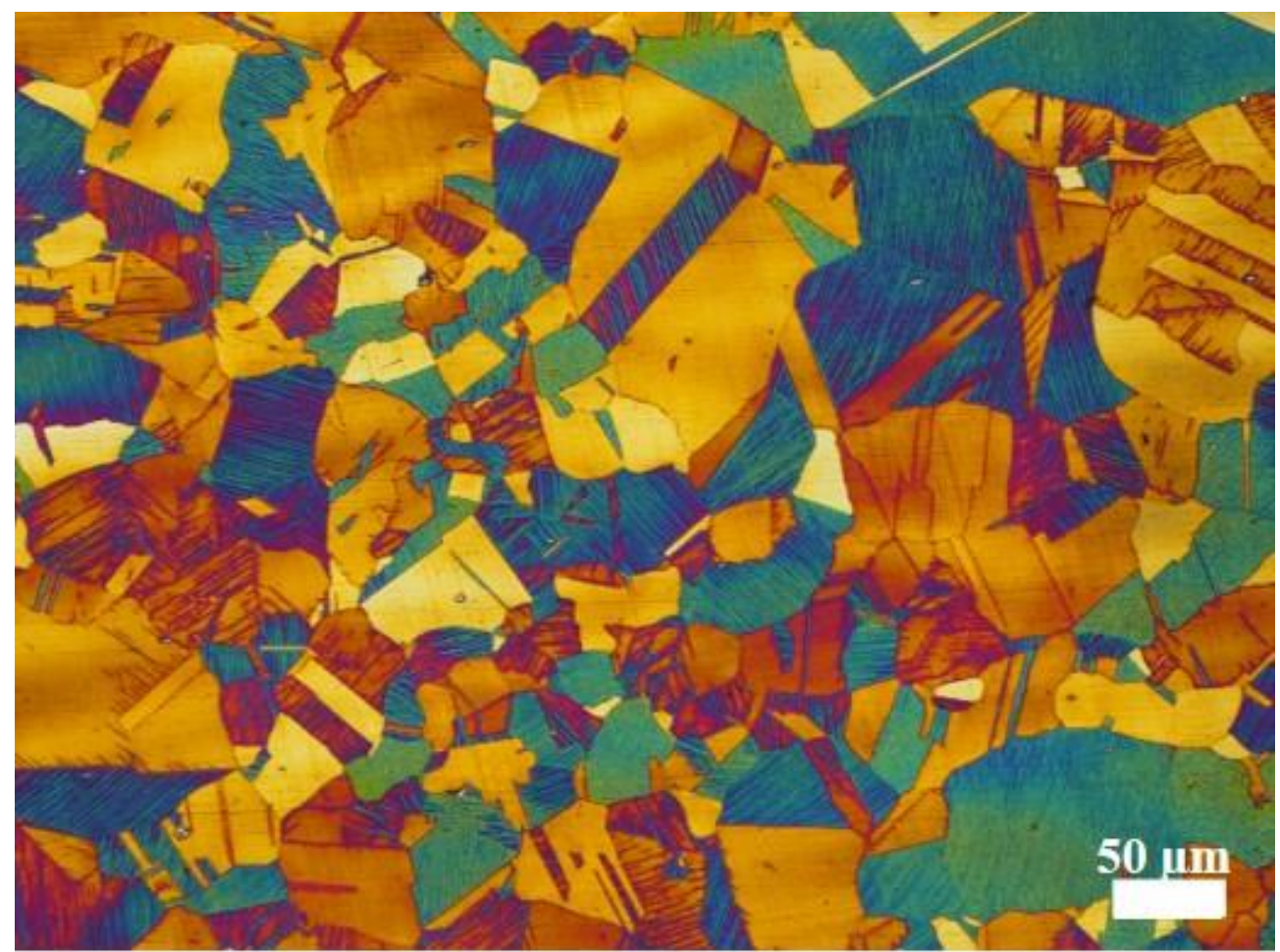


Figure 2. Bright field of optical micrographs at 200x magnification in the AISI 304 stainless steel using "aqua regia" $(\mathrm{HNO} 3+\mathrm{HCl})$ and "potassium metabisulfite" $(\mathrm{K} 2 \mathrm{~S} 2 \mathrm{O} 5)$ as the chemical etching.

\section{References}

[1] C Baghra et al, Optical and Laser Technology 69 (2015) p. 172-179.

[2] M Saravanan et al, Materials Today: Proceedings 5 (2018), p. 14392-14396.

[3] Gf Vander Voort “Color metallography”, ASM International, (2004) p.492-512.

[4] G Petzow "Metallographic etching”, ASM International, (1999) p. 39-40.

[5] The authors are grateful with the program Catedras CONACYT (Project 850 and 674) for their support. 